\title{
Risk of prostate cancer and thrombosis-related factor polymorphisms
}

\author{
SOMAYEHSADAT GHASEMI $^{1}$, AYDIN TAVAKOLI ${ }^{1}$, MOHAMAD MOGHADAM $^{2}$, MOHAMAD ALI ZARGAR $^{3}$, \\ MARYAM ABBASPOUR $^{1}$, NASIM HATAMNEJADIAN ${ }^{1}$ and AHMAD EBRAHIMI ${ }^{4}$ \\ ${ }^{1}$ Parseh Medical Genetics Counseling Center, Tehran; ${ }^{2}$ Hematology Research Center, Shiraz University \\ of Medical Science, Shiraz; ${ }^{3}$ Hasheminejad Kidney Center, Tehran; ${ }^{4}$ Cellular and Molecular Research Center, Research \\ Institute for Endocrine Sciences, Shahid Beheshti University of Medical Sciences, Tehran, Islamic Republic of Iran
}

Received August 19,2013; Accepted September 11, 2013

DOI: $10.3892 /$ br.2013.180

\begin{abstract}
Venous thromboembolism (VTE) is a complication commonly encountered in cancer patients and is considered to be a major cause of morbidity and mortality. The genetic polymorphisms of thrombophilic factors in cancer patients have been focused on during the last few years. However, the number of available studies on the association between prostate cancer and thromboembolic diseases is limited. Prostate cancer is one of the four major types of cancer and its development is affected by a variety of environmental and genetic factors. In the present study we aimed to focus on the effects of thromboembolic factor gene variations on the risk of prostate cancer. In order to conduct our prospective study, we used amplification-refractory mutation system-polymerase chain reaction to investigate three polymorphisms [factor $\mathrm{V}$ Leiden (FVL) G1691A, factor II (prothrombin, PTH) G20210A and methylenetetrahydrofolate reductase (MTHFR) C677T] in prostate cancer patients, via comparison with normal individuals. The results demonstrated no significant differences in FVL and PTH gene variations between cases and controls $(\mathrm{P}>0.05)$. Although some cases with the $\mathrm{T}$ allele of MTHFR 677 were identified, no significant solidarity was established by statistical analysis $(\mathrm{P}>0.05)$. Therefore, non-genetic factors that may disturb homeostatic balance should also be considered in future studies, in order to determine the exact association between VTE and prostate cancer.
\end{abstract}

\section{Introduction}

Cancer and thrombosis are closely interwined, as the coagulation system may affect tumor angiogenesis (1) and cancer

Correspondence to: Dr Ahmad Ebrahimi, Cellular and Molecular Research Center, Research Institute for Endocrine Sciences, Shahid Beheshti University of Medical Sciences, Velenjak, Tehran 1196543897, Islamic Republic of Iran

E-mail: ah_ebrahimi@sums.ac.ir

Key words: polymorphism, prostate cancer, thrombosis may constitute a risk factor for thromboembolic diseases (2). Several factors mediate this interaction, although the most extensively investigated mediators between these two disorders are the platelets, which play a double-edged role in the interplay between thrombosis and cancer. First, platelets are optimal carriers of growth factors to tumor cells. In addition, platelets may coat circulating tumor cells, protecting them from the immune system and assisting their invasion. Second, the prothrombotic properties of platelets may be stimulated through a cascade triggered by tumor cells (3).

Prostate cancer is the second most common cancer among men worldwide and the sixth most common cause of cancer-related mortality. As it is common in developed countries and its incidence is on the increase in developing countries (4), there is a pressing need for novel treatments and prediagnostic strategies for prostate cancer. Phylogenetic studies demonstrated a strong genetic basis for the incidence of this type of cancer (5), which may divert our studies to the genetic field. There have been several genetic studies on prostate cancer, particularly in the field of genetic variation research (6).

Thrombosis-related factor genetic variations have been recently focused on due to their effect on cancer (7). Although the interactions between thrombosis and prostate cancer is well established $(1,2)$, the number of available studies on the variations of thrombosis-related factors in patients with prostate cancer is limited (2). In this study, we focused on this area by evaluating the most common genetic variations of three factors: factor V Leiden (FVL), factor II (prothrombin, PTH) and methylenetetrahydrofolate reductase (MTHFR) enzyme.

The MTHFR enzyme, which is encoded by the MTHFR gene, is one of the factors of the coagulation system. A C-T polymorphism at nucleotide 677 in the MTHFR gene leads to increased levels of homocysteine, which is a risk factor for thrombosis (8). The other most extensively investigated thrombosis-related factors are FVL and PTH. FVL and PTH gene variations have been associated with protein $\mathrm{C}$ resistance, which is also a significant risk factor for venous thromboembolism (VTE) (7). MTHFR, FVL and PTH gene polymorphisms have been associated with different types of cancers $(1,9)$; however, there is a relative lack of studies on the association of these polymorphisms with prostate cancer. Our study aimed to evaluate the presence of FVL G1691A, PTH 
Table I. Primer set sequences.

\begin{tabular}{|c|c|c|c|}
\hline Gene & Sequence of forward primer & Sequence of reverse primer & $\begin{array}{l}\text { Amplicon } \\
\text { size (bp) }\end{array}$ \\
\hline Prothrombin & 5'GCACTGGGAGCATTGAGGATc $3^{\text {'a }}$ & 5'TCTAGAAACAGTTGCCTGGCAG3' & 34 \\
\hline $\begin{array}{l}\text { Factor V } \\
\text { Leiden }\end{array}$ & 5'GCAGATCCCTGGACAGACg $3^{\prime a}$ & 5'GGACTACTTGACAATTACTGTTCTCTTG3' & 152 \\
\hline MTHFR & 5'AAGCTGCGTGATGATGAACTt3'a & 5'TTGGAAGGTGCAAGATCAGAG3' & 226 \\
\hline $\begin{array}{l}\text { Hemoglobin } \\
\text { subunit } \beta\end{array}$ & 5'GTGCACCTGACTCCTGAGGAGA3' & 5'CCTTGATACCAACCTGCCCAG3' & 102 \\
\hline
\end{tabular}

Table II. Genotype frequency among cases and controls.

\begin{tabular}{|c|c|c|c|c|c|}
\hline \multirow[b]{2}{*}{ Groups } & \multicolumn{2}{|c|}{ MTHFR C677T } & \multicolumn{2}{|c|}{ Prothrombin G20210A } & \multirow{2}{*}{$\frac{\text { FVL G1691A }}{\text { GG }(\%)}$} \\
\hline & $\mathrm{CC}(\%)$ & $\mathrm{TC}(\%)$ & GG $(\%)$ & $\mathrm{AG}(\%)$ & \\
\hline Cases & $27(90.0)$ & $3(10.0)$ & $29(96.7)$ & $1(3.3)$ & $30(100.0)$ \\
\hline Controls & $34(85.0)$ & $6(15.0)$ & $40(100.0)$ & $0(0.0)$ & $40(100.0)$ \\
\hline
\end{tabular}

MTHFR, methylenetetrahydrofolate reductase; FVL, factor V Leiden.

G20210A and MTHFR C677T polymorphisms among Iranian prostate cancer patients.

\section{Materials and methods}

Subjects. A total of 30 patients and 40 controls were recruited from Hashemnejad Hospital, Tehran, Iran. The patients enrolled in the study had prostate-specific antigen (PSA) levels $>20 \mathrm{ng} / \mathrm{ml}$, Gleason scores $>7$ and a median age of 64 years (range, 49-78 years). The selected controls had PSA levels of $<4 \mathrm{ng} / \mathrm{ml}$ and were of the same median age.

All the clinical procedures were approved by the local Ethics Committee of Hashemnejad Hospital and the participants provided informed consent prior to their inclusion in the study.

Methods. Genomic DNA was extracted from peripheral blood samples obtained from the cases and controls using standard protocols. The amplification-refractory mutation system (ARMS) was used to determine the single-nucleotide polymorphisms (SNPs) in each sample. In addition to designing the ARMS-polymerase chain reaction (PCR) primer sets for each gene polymorphism, we used the primer pairs for amplifying the hemoglobin subunit $\beta$ gene in each sample to provide an internal control (Table I). The PCR cycles were conducted using Flexigene (Techne Corporation, Minneapolis, MN, USA). The amplification programs for each primer pair are described below.

All the PCR procedures were performed in a total volume of $25 \mu \mathrm{l}$. The PCR reaction for MTHFR consisted of an initial denaturation step for $5 \mathrm{~min}$ at $94^{\circ} \mathrm{C}$, followed by 35 cycles of denaturation for $40 \mathrm{sec}$ at $94^{\circ} \mathrm{C}, 50 \mathrm{sec}$ of annealing at $62^{\circ} \mathrm{C}$ and an extension step at $72^{\circ} \mathrm{C}$ for $45 \mathrm{sec}$. To amplify FVL, PCR was performed under the following conditions: initial denaturation at $94^{\circ} \mathrm{C}$ for 5 min and 35 cycles with 3 segments of denaturation at $94^{\circ} \mathrm{C}$ for $1 \mathrm{~min}$, annealing at $60^{\circ} \mathrm{C}$ for $1 \mathrm{~min}$ and extension at $72^{\circ} \mathrm{C}$ for $30 \mathrm{sec}$. For SNP analysis of the PTH gene, PCR consisted of an initial denaturation at $94^{\circ} \mathrm{C}$ for 5 min and 35 cycles with 3 segments of denaturation at $94^{\circ} \mathrm{C}$ for $1 \mathrm{~min}$, annealing at $60^{\circ} \mathrm{C}$ for $1 \mathrm{~min}$ and extension at $72^{\circ} \mathrm{C}$ for $1 \mathrm{~min}$. All the PCR reactions terminated with a final elongation for $5 \mathrm{~min}$ at $72^{\circ} \mathrm{C}$.

The PCR products were separated using electrophoresis on $2 \%$ agarose gel supplemented with SYBR-Green for DNA product visualization under UV light.

Statistical analysis. The statistical analysis was performed using SPSS software, version 19.0 (SPSS Inc., Chicago, IL, USA). Allelic and genotypic associations were evaluated by the Chi-square and Fisher's exact tests.

\section{Results}

SNP detection. We successfully detected the three previously described SNPs (rs1801133, rs6025 and rs1799963) in 30 prostate cancer patients and 40 healthy individuals that were used as controls. The distribution of the genotype frequencies of FVL G1691A, PTH G20210A and MTHFR C677T are presented in Table II.

FVL mutations. FVL mutations of the homozygous or heterozygous genotype were not detected in any of the cases 
or the controls. All the subjects were found to be normal homozygous.

PTH mutations. There were no statistical differences between the two groups with regard to PTH G20210A mutation $(\mathrm{P}=0.429)$. However, the heterozygous form was detected in one patient $(3.3 \%)$.

MTHFR mutations. The MTHFR C677T genotype heterozygous mutation was detected in 3 cases (10\%) and 6 controls (15\%). However, there was no statistically significant association between this mutation and the risk of prostate cancer $(\mathrm{P}=0.404)$.

\section{Discussion}

Prostate cancer is the most common type of cancer among men (10). Therefore, there is a need for novel prevention and treatment strategies for this disease. Although there are certain clinical prostate cancer diagnostic tests available, such as the measurement of PSA or early prostate cancer antigen-3 levels $(11,12)$, a prediagnostic genetic test is required to screen unsuspected cancers. Accordingly, over the last few decades, scientists have focused on linking SNPs to prostate cancer and several SNPs that substantially affect the risk of prostate cancer were identified (6).

In addition, the interactions between different types of cancer and VTE factor gene variations have been established $(1,9,13)$.

The association of the MTHFR 677TT genotype with certain types of cancer, such as an elevated risk for thyroid carcinoma (14), bladder cancer in a Turkish population (15) and a reduced risk of colorectal cancer (13), was previously demonstrated. However, Jakubowska et al (16) reported no association between MTHFR 677 polymorphisms and breast cancer and Kang et al (17) observed no differences in the distribution of this variant in colorectal cancer patients compared to normal individuals. Our results also demonstrated no interaction between prostate cancer and the MTHFR variant in the Iranian population. Although the higher frequency of the TT genotype of MTHFR 677 in the control group did not reach a statistical significance, it may complicate the interactions between thrombosis and prostate cancer. The substitution of $\mathrm{T}$ in nucleotide 677 of the MTHFR gene produces an enzyme with reduced activity and results in an increase in the levels of homocysteine (18). Hyperhomocysteinemia is also a significant risk factor for thrombosis (8). The presence of an allele which leads to thrombosis in our control group rather than the case group was an interesting issue and our data should be extended to address this issue more confidently. In addition, this polymorphism should be evaluated in prostate cancer under different conditions, such as surveying the variant in patients with and without VTE. Another example is the study of Ozkan et al (9) that acclaimed a significant difference between cancer patients with and without thrombosis in terms of the presence of the MTHFR mutation.

An increased risk for colorectal cancer was previously demonstrated for homozygous carriers of the FVL polymorphism compared to non-carriers (19). In addition, the contribution of FVL mutations in the oncogenesis of oral cancer was demonstrated by Vairaktaris et al (1). Our study did not identify such an interaction with prostate cancer. The direct outcome of this finding was that the FVL G1691A polymorphism does not affect the risk of prostate cancer. However, two points should be considered. First, this polymorphism has been a subject of controversy. Although no association was reported between FVL mutations and cancer patients by Ozkan et al (9), a significant effect of FVL on thrombosis in patients with malignant diseases was established by Pihusch et al (20). Second, the SNP allele frequencies vary significantly between human populations. This controversy may result from the differences between the studied populations. In the Iranian population assessed by the present study, there was no observed association between FVL mutations and prostate cancer; however, data collection from other populations is required to verify this null association.

PTH G20210A carriers were shown to be at reduced risk for colorectal cancer in a German population (19). However, Ozkan et al (9) reported no significant association between PTH mutations and cancer, there was no association with lung cancer (21) and we did not observe any significant interaction in Iranian prostate cancer patients. These data indicate that PTH G20210A is not significantly associated with cancer. However, similar to FVL, allele frequencies from different population must be assessed to verify our conclusions.

In conclusion, this study revealed no association between the risk of prostate cancer and the most significant thrombosis-related factor gene polymorphisms in an Iranian population. However, although we were unable to demonstrate such an association, a large and prospective study may yield different results.

\section{Acknowledgements}

We would like to thank the Hashemnejad Hospital of Tehran for kindly providing the blood samples used in this study.

\section{References}

1. Vairaktaris E, Yapijakis C, Wiltfang J, et al: Are factor V and prothrombin mutations associated with increased risk of oral cancer? Anticancer Res 25: 2561-2565, 2005.

2. Van Hemelrijck M, Adolfsson J, Garmo H, et al: Risk of thromboembolic diseases in men with prostate cancer: results from the population-based PCBaSe Sweden. Lancet Oncol 11: 450-458, 2010.

3. Trikha M and Nakada MT: Platelets and cancer: implications for antiangiogenic therapy. Semin Thromb Hemost 28: 39-44, 2002.

4. Baade PD, Youlden DR and Krnjacki LJ: International epidemiology of prostate cancer: geographical distribution and secular trends. Mol Nutr Food Res 53: 171-184, 2009.

5. Zeegers MP, Jellema A and Ostrer H: Empiric risk of prostate carcinoma for relatives of patients with prostate carcinoma: a meta-analysis. Cancer 97: 1894-1903, 2003.

6. Eeles RA, Kote-Jarai Z, Giles GG, et al: Multiple newly identified loci associated with prostate cancer susceptibility. Nat Genet 40: 316-321, 2008.

7. Ramacciotti E, Wolosker N, Puech-Leao P, et al: Prevalence of factor V Leiden, FII G20210A, FXIII Val34Leu and MTHFR C677T polymorphisms in cancer patients with and without venous thrombosis. Thromb Res 109: 171-174, 2003.

8. Eroglu A, Egin Y, Cam R and Akar N: The 19-bp deletion of dihydrofolate reductase (DHFR), methylenetetrahydrofolate reductase (MTHFR) C677T, factor V Leiden, prothrombin G20210A polymorphisms in cancer patients with and without thrombosis. Ann Hematol 88: 73-76, 2009.

9. Ozkan M, Sivgin S, Kocyigit I, et al: Do thrombophilic gene mutations have a role on thromboembolic events in cancer patients? Asia Pac J Clin Oncol 8: e34-e41, 2012. 
10. Pectasides D, Pectasides E, Papaxoinis G, et al: Combination chemotherapy with docetaxel, vinorelbine and estramustine phosphate in metastatic androgen-resistant prostate cancer: a single institution experience. Anticancer Res 29: 769-775, 2009.

11. Bourdoumis A, Papatsoris AG, Chrisofos M, Efstathiou E, Skolarikos A and Deliveliotis C: The novel prostate cancer antigen 3 (PCA3) biomarker. Int Braz J Urol 36: 665-669, 2010.

12. Hansel DE, DeMarzo AM, Platz EA, et al: Early prostate cancer antigen expression in predicting presence of prostate cancer in men with histologically negative biopsies. J Urol 177: 1736-1740, 2007.

13. Kennedy DA, Stern SJ, Matok I, et al: Folate intake, MTHFR polymorphisms, and the risk of colorectal cancer: a systematic review and meta-analysis. J Cancer Epidemiol 2012: 952508, 2012.

14. Ozdemir S, Silan F, Hasbek Z, et al: Increased T-allele frequency of $677 \mathrm{C}>\mathrm{T}$ polymorphism in the methylenetetrahydrofolate reductase gene in differentiated thyroid carcinoma. Genet Test Mol Biomarkers 16: 780-784, 2012.

15. Izmirli M, Inandiklioglu N, Abat D, et al: MTHFR gene polymorphisms in bladder cancer in the Turkish population. Asian Pac J Cancer Prev 12: 1833-1835, 2011.
16. Jakubowska A, Rozkrut D, Antoniou A, et al: Association of PHB $1630 \mathrm{C}>\mathrm{T}$ and MTHFR $677 \mathrm{C}>\mathrm{T}$ polymorphisms with breast and ovarian cancer risk in BRCA1/2 mutation carriers: results from a multicenter study. Br J Cancer 106: 2016-2024, 2012.

17. Kang BS, Ahn DH, Kim NK and Kim JW: Relationship between metabolic syndrome and MTHFR polymorphism in colorectal cancer. J Korean Soc Coloproctol 27: 78-82, 2011.

18. Shannon B, Gnanasampanthan S, Beilby J and Iacopetta B A polymorphism in the methylenetetrahydrofolate reductase gene predisposes to colorectal cancers with microsatellite instability. Gut 50: 520-524, 2002.

19. Vossen CY, Hoffmeister M, Chang-Claude JC, Rosendaal FR and Brenner H: Clotting factor gene polymorphisms and colorectal cancer risk. J Clin Oncol 29: 1722-1727, 2011.

20. Pihusch R, Danzl G, Scholz M, et al: Impact of thrombophilic gene mutations on thrombosis risk in patients with gastrointestinal carcinoma. Cancer 94: 3120-3126, 2002.

21. Arslan S, Manduz S, Epozturk K, Karahan O and Akkurt I: Association of deep venous thrombosis with prothrombotic gene polymorphism identified in lung cancer cases. Mol Biol Rep 38: 2395-2400, 2011. 